\title{
AS TÉCNICAS DA SINALIZAÇÃO E DO JULGAMENTO- -ALERTA DE SUPERAÇÃO DO PRECEDENTE JUDICIAL: Estudo de Caso
}

\author{
http://dx.doi.org/10.21527/2176-6622.2019.52.77-91
}

Recebido em: 1이리일

Modificações requeridas em: 19/4/2019

Aceito em: 31/7/2019

\section{Elmer da Silva Marques}

Doutor em Direito pela Universidade Federal do Paraná. Mestre em Direito pela Universidade Estadual de Londrina. Bacharel em Direito pela Universidade Estadual de Maringá. Professor-adjunto do curso de Direito da Universidade Estadual do Oeste do Paraná, campus de Francisco Beltrão/PR. http://lattes.cnpq.br/7131088598772071. elmer_adv@yahoo.com.br

\section{Guilherme Machado Aguiar}

Acadêmico do curso de Direito da Universidade Estadual do Oeste do Paraná, campus de Francisco Beltrão/PR. Integrante do Projeto de Iniciação Científica "Decisões judiciais e tribunais superiores: análise sob a perspectiva da filosofia da linguagem". http://lattes.cnpq.br/1113187659470184

guil_machado@outlook.com

\section{Juliane Gloria Sulzbach}

Acadêmica do curso de Direito da Universidade Estadual do Oeste do Paraná, campus de Francisco Beltrão/PR. Integrante do Projeto de Iniciação Científica "Decisões judiciais e tribunais superiores: análise sob a perspectiva da teoria dos precedentes judiciais obrigatórios". http://lattes.cnpq.br/2209471411119033. juhliane_@hotmail.com

\section{RESUMO}

O presente artigo tem por objetivo a análise de decisão proferida pelo STF na qual este anunciou a possibilidade de rever o entendimento sobre questão jurídica que vinha sendo aplicado de forma pacífica. Especial atenção será dada à reação dos ministros do STF à tentativa de superação de entendimento promovida pelo ministro Dias Toffoli, bem como as consequências jurídicas que se poderiam inferir da manifestação dos demais Ministros, naquele julgamento, no âmbito de um sistema de precedentes judiciais obrigatórios. Para tanto, analisou-se o acórdão proferido na QO-AO 1814/MG (metodologia empírica), bem como conceitos e características do sistema de precedentes judiciais e das técnicas da sinalização e do julgamento-alerta de superação do precedente judicial (metodologia analítico-conceitual). Por fim, propôs-se uma resposta correta ao problema enfrentado (dimensão metodológica normativa): caberia ao STF ter, mediante fundamentação adequada, reanalisado a possibilidade de superação do precedente judicial, tendo em vista o julgamento-alerta realizado anteriormente.

Palavras-chave: Julgamento-alerta. Precedentes judiciais obrigatórios. Superação de entendimento.

\section{THE TECHNIQUES OF SIGNALING AND JUDGMENT-ALERT OF BINDING PRECEDENTS OVERRULING: A CASE STUDY}

\section{ABSTRACT}

This study analyzes the decision handed down by the Brazilian Supreme Court in which the Court announced the possibility of overruling the ratio decidendi of a precedent that had been applied in a stable manner. Special attention is paid to the Brazilian Supreme Court Ministers' reactions to the Minister Dias Toffoli attempt to overrule the ratio decidendi, as well as to the legal consequences that could be inferred from the other Ministers manifestations in that decision within a system of biding precedents. Therefore, this paper analyses the decision issued in the QO-AO1814/MG judgment (empirical method), as well as analyses the stare decisis system and its techniques of signaling and judgment-alert of binding judicial precedent overruling (analytical-conceptual method). Finally, it was proposed a correct answer to the problem faced (normative-methodological perspective): the Brazilian Supreme Court, having previously issued an overruling judgment-alert, should have reanalysed the possibility of overruling by adequate reasoning,

Keywords: Judgment-alert. Binding precedents. Overruling.

\section{SUMÁRIO}

1 Introdução. 2 A Segurança Jurídica e a Superação do Precedente Judicial: As Técnicas da Sinalização e do Julgamento-Alerta. 3 A Competência do Supremo Tribunal Federal para Conhecer e Julgar Ações que Visam a Impugnar Atos do CNJ. 4 A Tentativa de Overruling pelo Ministro Dias Toffoli. 5 O Alerta de Possível Superação de Entendimento e as Consequências Jurídicas em um Sistema de Precedentes Judiciais Obrigatórios. 6 Sistematização dos Votos Proferidos no Julgamento da AO 1814/MG. 7 Decisões Posteriores ao Julgamento da AO 1814/MG. 8 Considerações Finais. 9 Referências. 


\section{INTRODUÇÃO}

A igualdade e a segurança jurídica são dois direitos fundamentais previstos no caput do artigo 5o da Constituição Federal. Tanto a igualdade quanto a segurança jurídica podem ser estudadas sob diversas perspectivas e abordagens. Dentre os vários ângulos possíveis de estudo, a análise da igualdade e da segurança jurídica ante as decisões judiciais vem ganhando destaque.

Nesse sentido, a compreensão de que casos iguais devam receber o mesmo tratamento, representado pelo sempre citado brocardo treat like cases alike, é um dos fundamentos que embasam o estudo e a defesa, por muitos, da adoção de um sistema de precedentes judiciais obrigatórios em terra pátria. É um princípio básico da administração da justiça que casos iguais devam ser julgados da mesma forma (like cases should be decided alike) (CROSS; HARRIS, 2004, p. 3).

O julgamento de casos iguais de forma diferente é fenômeno que já foi denominado de jurisprudência lotérica, o qual ocorre quando a mesma questão jurídica "é julgada por duas ou mais maneiras diferentes. Assim, se a parte tiver a sorte de a causa ser distribuída a determinado Juiz, que tenha entendimento favorável da matéria jurídica envolvida, obtém a tutela jurisdicional; caso contrário, a decisão não lhe reconhece o direito pleiteado" (CAMBI, 2001, p. 111). O fenômeno da jurisprudência lotérica ofenderia, a um só tempo, ambos os direitos fundamentais, a saber: a igualdade jurídica, na medida em que pessoas em idêntica situação jurídica receberiam tratamento jurisdicional diferenciado; a segurança jurídica, quando a falta de uniformidade, coerência e integridade das decisões judiciais impediria a prévia compreensão do sentido do Direito e a possibilidade de a sociedade se organizar de modo a agir de acordo com as disposições normativas.

Defende-se, assim, um sistema de precedentes judiciais obrigatórios para, a um só tempo, concretizar o direito de igualdade de todos perante a lei - todos os que se encontram em situação jurídica idêntica devem receber o mesmo tratamento jurisdicional - e o direito à segurança jurídica - a construção de um sistema de decisões judiciais uniformes, coerentes e íntegras garantiria a previsibilidade de aplicação do Direito pelo órgão jurisdicional.

Defender a obediência aos precedentes judiciais força-nos a reconhecer que, em um determinado momento, o entendimento antes adotado pode se tornar defasado pela evolução da sociedade, da cultura, da tecnologia, do texto legislativo, da política, etc. Tornando-se o precedente obsoleto, o entendimento adotado deverá ser superado, de modo a adequar o Direito à nova realidade. A superação do precedente - chamada na doutrina e na tradição do common law de overruling - é fenômeno de evolução do direito jurisprudencial e garante sua adaptação aos novos tempos. Um sistema de precedentes judiciais obrigatórios é um sistema estável, e não inflexível. A possibilidade de se superar um entendimento adotado em um precedente não ofende o sistema de stare decisis (POWELL JR., 1990, p. 284). Em outras palavras, um sistema de precedentes judiciais busca preservar a estabilidade, mas deixa espaço para a inovação e a correção de erros (FARBER, 2005, p. 1.175).

Surge, novamente, a questão da segurança jurídica: a superação do precedente judicial pode surpreender a sociedade que já havia adaptado e adequado seu comportamento ao precedente superado, atingindo a previsibilidade do Direito e, consequentemente, a segurança jurídica. Debater acerca da superação do precedente demanda tratar da segurança jurídica: Como superar um precedente judicial, estabelecendo novas pautas de conduta jurídica à sociedade, sem ofender a garantia da segurança jurídica?

Muito pode ser escrito sobre o assunto. No presente trabalho, o corte metodológico selecionou as chamadas técnicas da sinalização - signaling - e do julgamento-alerta, pelas quais o tribunal anuncia à sociedade que pretende rever ou rediscutir o entendimento até então adotado sobre uma determinada questão jurídica. A sociedade é, assim, avisada com antecedência de que o precedente judicial que trata de uma determinada questão jurídica sofreu - ou vem sofrendo - um desgaste e será, em um futuro mais ou menos próximo, rediscutido e, eventualmente, superado. Com isso, visa-se a mitigar eventual ofensa à segurança jurídica.

Para fins do presente trabalho, e ainda dentro do corte metodológico efetuado, selecionou-se, para estudo de caso, o julgamento da Questão de Ordem na Ação Originária no 1.814/MG, julgado pelo Supremo Tribunal Federal em 24 de setembro de 2014, referente à competência daquele tribunal para conhecer e julgar demandas que visam a impugnar atos do Conselho Nacional de Justiça - CNJ. 
Inicialmente, apresentar-se-ão as concepções adotadas neste trabalho acerca dos institutos jurídicos abordados, como a segurança jurídica, o overruling - a superação do precedente - o signaling e o julgamento-alerta (metodologia analítico-conceitual).

Em seguida, promover-se-á a análise da Questão de Ordem na Ação Originária no 1.814/MG, em especial a tentativa do ministro Dias Toffoli, em voto vencido, de superar o entendimento adotado pelo STF acerca de sua competência para conhecer e julgar ações que visam à impugnação de atos do CNJ. Especial atenção será dada à reação dos demais ministros ao voto do ministro Dias Toffoli, bem como às consequências jurídicas que se poderiam inferir da manifestação dos ministros, naquele julgamento, no âmbito de um sistema de precedentes judiciais obrigatórios (metodologia empírica).

Ressalta-se, por oportuno, reconhecermos que, no momento, não há a prática de um sistema de precedentes judiciais vinculantes no Brasil, mas, sim, de adoção de técnicas de uniformização de jurisprudência que visam à consolidação do entendimento dos tribunais quanto à interpretação e aplicação das normas jurídicas. A conclusão alcançada pelo trabalho, entretanto, não restou prejudicada.

\section{A SEGURANÇA JURÍDICA E A SUPERAÇÃO DO PRECEDENTE JUDICIAL: As Técnicas da Sinalização e do Julgamento-Alerta}

A compreensão da segurança jurídica está intrinsecamente ligada ao entendimento sobre precedentes judiciais, ao menos no que diz respeito à dimensão da igualdade de tratamento dispensada pelo Poder Judiciário aos jurisdicionados. Se a adoção de um sistema de precedentes judiciais obrigatórios concretiza a segurança jurídica, sua adoção é apropriada e exigida pelo Estado de Direito constitucionalmente estabelecido, uma vez que "a segurança jurídica, vista como estabilidade e continuidade da ordem jurídica e previsibilidade das consequências jurídicas de determinada conduta, é indispensável para a conformação de um Estado que pretenda ser 'Estado de Direito'" (MARINONI, 2016, p. 95).

Com a promulgação da Constituição Federal de 1988 e o advento de um novo Código de Processo Civil ocorrido em 2015, destaca-se a necessidade de previsibilidade do Direito para a sociedade decorrente do princípio da segurança jurídica, sendo de notória importância para a adoção de um sistema de precedentes judiciais vinculantes no Brasil, uma vez que tais institutos têm ligação direta.

Quando se analisa a segurança jurídica a partir da perspectiva de previsibilidade que os cidadãos possuem do tratamento dispensado pelo Judiciário aos jurisdicionados, o law in books não é suficiente, como também os textos constitucional e legislativo não são suficientes para garantir a segurança jurídica. É necessário uma prática jurídica que assegure, na aplicação da lei, a igualdade de tratamento e a segurança jurídica, esta entendida como previsibilidade das ações do aplicador da lei.

A segurança jurídica pode ser vista como valor, fato ou norma-princípio. A segurança jurídica como valor é constituída em um ideal a ser buscado em razão de influências sociais, históricas, econômicas ou políticas. No que diz respeito à segurança jurídica como fato, manifesta-se pela possibilidade de o indivíduo prever os resultados jurídicos decorrentes de fatos ou comportamentos. Nessa proposição, a segurança jurídica está ajustada ao aspecto da previsibilidade das relações. Por seu turno, a segurança jurídica como norma-princípio "denota [...] um juízo prescritivo a respeito daquilo que deve ser buscado de acordo com determinado ordenamento jurídico" (ÁVILA, 2011, p. 109).

Dessa maneira, a criação e a aplicação das normas jurídicas, mediante ato interpretativo do texto legislativo, são concretizadas sob a ideia de previsibilidade, proporcionando que os cidadãos antecipem os efeitos jurídicos futuros dos atos presentes. Verifica-se, desse modo, que a segurança jurídica, vista como norma-princípio, auxilia como uma direção prescritiva não somente ao legislador, mas também ao aplicador do Direito como fundamento para a adoção de um sistema de precedentes judiciais vinculantes e relacionando-se estritamente com o instituto do overruling. A previsibilidade do Direito é vista aqui - levando em conta a segurança jurídica como norma-princípio - como a ideia de proteger as decisões judiciais, haja vista que a superação de determinado precedente pode vir a mudar completamente o panorama de um ordenamento jurídico (ÁVILA, 2011, p. 109). 
Ademais, as preocupações com a segurança jurídica, levando em consideração a certeza, cognoscibilidade e duração da jurisprudência solidificada, é importante para a estabilidade do entendimento consolidado dos tribunais. Assim, mudanças da jurisprudência devem ser realizadas de maneira responsável, controlável e com considerações à segurança jurídica no tempo. Deve haver um equilíbrio entre as exigências de segurança jurídica e a proteção das posições individuais estáveis (CABRAL, 2013, p. 17-18).

Hodiernamente, o Estado de Direito precisa atuar na segurança jurídica com maior flexibilidade, sem relacioná-la com palavras como "inalterabilidade", "indiscutibilidade", "imunização" e "intangibilidade". A segurança jurídica deve ser vista como segurança-continuidade, sendo esta definida como mudança com consistência, uma forma de não bloquear totalmente as mudanças e, simultaneamente, preservar a segurança jurídica. Dessa forma, "a continuidade jurídica atribui ao sistema apenas uma duração tendencial, sem precluir ou impedir a alteração de conteúdos estáveis" (CABRAL, 2013, p. 25-27).

Vejamos o exemplo que nos é trazido por Antonio do Passo Cabral (2013, p. 24):

Imaginemos um caso em que, numa determinada comarca ou subseção judiciária, durante muito tempo o juízo se manifeste em um determinado sentido; é razoável pensar que não só os advogados, membros do Ministério Público, serventuários, enfim, aqueles que trabalhem diretamente com o juízo, mas também os cidadãos, os jurisdicionados, recebam esta reiteração como o sinal de um padrão de resposta do Poder Judiciário para determinada matéria, e, portanto, possam construir suas programações de vida, de negócios etc. com base naquele entendimento.

O juiz, subordinado ao sistema de precedentes, se quiser afastá-lo, assume o dever de apresentar forte carga argumentativa para justificar a sua não aplicação, seja por distinguishing (distinção do precedente), seja por overruling (superação do precedente).

Se o argumento que embasa o precedente é insuficiente e se os órgãos vinculados o percebem como errado, injusto e absurdo, há formas de buscar a redução da sua ratio decidendi, pois a aplicação do precedente não é automática (MELLO; BAQUEIRO, 2018, p. 685).

Assim, o overruling, em geral, é somente realizado pela própria Corte que produziu o precedente a ser superado. Pertinente, aqui, a lição de Luiz Guilherme Marinoni (2016, p. 200):

Lembre-se que no common law os precedentes são revogados fundamentalmente mediante o que se denomina de overruling. Não há dúvida que o Supremo Tribunal Federal pode revogar os seus precedentes. Pode revogar, note-se bem, as rationes decidendi das suas decisões. Para tanto, contudo, tem de se desincumbir de pesado ônus argumentativo, demonstrando que as razões que levaram à elaboração do precedente que se quer revogar não são mais sustentáveis em virtude de motivos novos, que devem ser mostrados presentes. Tais "motivos novos", é evidente, estão muito longe de novos entendimentos pessoais acerca da questão já debatida.

Ocorre a defasagem do precedente judicial diante de um novo contexto social, histórico e cultural. Sua estrutura argumentativa, reunida aos argumentos fáticos e jurídicos que o fundamentam, está ultrapassada, sendo inevitável a superação do entendimento até então firmado. Quando ocorre a superação do precedente - o chamado overruling - há a ressignificação do Direito e tanto a sociedade quanto o sistema jurídico adaptam-se em torno daquele novo precedente, visto como confiável para futuras soluções análogas.

Diante disso, um precedente está em condições de ser superado quando perde a chance de corresponder aos padrões de congruência social, verificando que este passou a negar proposições morais, políticas e de experiência da sociedade (MARINONI, 2016, p. 252). Nesse sentido, a técnica do overruling pode ofender a segurança jurídica, pois a sociedade organizada em torno do precedente estava orientada e adaptada a seguir determinadas condutas.

Faz-se necessário, portanto, a adoção de técnicas para minimizar os efeitos deletérios do overruling à segurança jurídica, pois a mudança de entendimento atinge diretamente a previsibilidade dos cidadãos que organizaram suas vidas a partir da pauta de conduta estabelecida pelo precedente cujo entendimento foi superado pelo tribunal. 
Dentre as técnicas adotadas, tem-se a modulação dos efeitos da decisão judicial que promove a superação do precedente. Em regra, a eficácia temporal da revogação de um precedente é retroativa, vez que, tradicionalmente, a decisão judicial resolve determinado caso que ocorreu no passado (MARINONI, 2016, p. 269).

Por sua vez, aplicar o novo entendimento judicial a outros casos pode, igualmente, ocasionar ofensa à segurança jurídica, pois aqueles casos podem se fundar em fatos passados que ocorreram orientados pelo entendimento jurisprudencial superado.

Para atender ao interesse social e à segurança jurídica, os tribunais superiores podem proceder à proteção daqueles valores de três formas: a) por intermédio da sinalização (signaling), quando o Tribunal informa a sociedade que irá promover a superação de seu entendimento em um futuro julgamento; b) por meio do prospective overruling, quando o Tribunal, atento ao princípio da proteção da confiança, promove a superação do precedente judicial mas determina que a decisão somente iniciará a produção de efeitos a partir da própria decisão; e, c) mediante o prospective overruling, quando a corte fixa um momento futuro para que a decisão que promoveu a superação do precedente comece a produzir efeitos (MARINONI; ARENHART; MITIDIERO, 2015, p. 875-876). Adicione-se, ainda, a técnica do julgamento-alerta, que será apresentada em momento apropriado no presente trabalho.

Para evitar ofensa à segurança jurídica, há a possibilidade de modulação dos efeitos da decisão judicial, visando a proteger a segurança jurídica e a previsibilidade do ordenamento jurídico, como expresso no $\S 30$ do artigo 927 do Código de Processo Civil, permitindo a modulação de efeitos para atender ao "interesse social" e à "segurança jurídica". O Tribunal, antes de promover a modulação dos efeitos da decisão, deve fazer, motivadamente, um exame do eventual interesse social e da segurança jurídica em jogo.

Existem cinco formas de se modular os efeitos da decisão judicial que promove a alteração de entendimento jurídico: a) aplicação retroativa pura, em que o novo entendimento abrange os fatos passados, inclusive aqueles relativos a decisões transitadas em julgado, com a possibilidade de utilização de ação rescisória; b) aplicação retroativa clássica: em que o tribunal iria aplicar a sentença aos fatos ocorridos antes da formação do novo precedente, exceto aos que já transitaram em julgado; c) aplicação prospectiva pura: quando o novo precedente se aplica apenas aos fatos posteriores, sequer sendo aplicado às partes litigantes; d) aplicação prospectiva clássica: aplicando-se apenas aos fatos novos, com a exceção das partes no caso concreto abrangido pelo novo precedente; e e) aplicação prospectiva a termo: em que o tribunal fixa uma data ou condição para a eficácia do precedente (DIDIER JR.; BRAGA; OLIVEIRA, 2018, p. 582).

A modulação dos efeitos da decisão que materializa alteração jurisprudencial, constitui importante instrumento de garantia dos postulados da segurança jurídica e da proteção da confiança. A ela somam-se as técnicas da sinalização e do julgamento-alerta, objetos do presente estudo, demonstrando a tendência de preocupação com que as decisões judiciais, em um sistema de precedentes judiciais, garantam a segurança jurídica daqueles que se orientaram de acordo com a orientação jurisprudencial fixada anteriormente.

Pela técnica da sinalização (signaling) e do julgamento-alerta, as Cortes Supremas podem manifestar-se publicamente sobre a preocupação com a adequação da solução contida no precedente, preparando o caminho para uma superação suave, não abrupta, do precedente (MITIDIERO, 2013, p. 125).

A técnica da sinalização, também conhecida por signaling, pode ser definida como um mecanismo prévio para a revogação de precedentes. $O$ tribunal, percebendo a desatualização de um precedente, sinaliza, isto é, anuncia que irá superá-lo, fazendo com que ele se torne incapaz de servir como base para a confiança dos jurisdicionados. Nesses termos, atua como parâmetro inicial da revogação prospectiva (DIDIER JR.; BRAGA; OLIVEIRA, 2018, p. 583). O signaling pode mitigar eventual ofensa à segurança jurídica por promover um aviso prévio à sociedade de que aquele entendimento será superado em um julgamento futuro. Na lavra de Luiz Guilherme Marinoni, pela utilização da técnica da sinalização (technique of signaling),

[...] o tribunal não ignora que o conteúdo do precedente está equivocado ou não mais deve subsistir, mas, em virtude da segurança jurídica, deixa de revogá-lo, preferindo apontar para a sua perda de consistência e sinalizar para a sua futura revogação. [...] Mantém-se o precedente unicamente em virtude da segurança jurídica, da previsibilidade dada aos jurisdicionados e da confiança que o Estado deve tutelar, ainda que não se duvide que a sua manutenção está em desacordo com o ideal de direito prevalente à época (2016, p. 237). 
Importante diferenciação é feita por Antonio do Passo Cabral, para quem o anúncio de superação do precedente pode se dar por meio da técnica do julgamento-alerta, instituto semelhante ao signaling, mas que com este não se confunde: tanto a técnica quanto a finalidade do signaling são diversas da decisão-alerta, pois "através do signaling, a Corte reconhece que o conteúdo do precedente está errado e deve ser superado mas, em nome da segurança jurídica, afirma apenas sua 'perda de consistência', sinalizando a sua futura revogação". Utilizando-se da técnica do signaling, o tribunal não duvida da necessidade de superação do precedente, ou seja, "já existe uma conclusão pela superação do precedente, mas o overruling não é pronunciado de imediato para não ferir a segurança jurídica" (CABRAL, 2013, p. 39).

Por sua vez, valendo-se da técnica do julgamento-alerta ou "anúncio público", o tribunal informa a sociedade sobre a possibilidade de o tribunal mudar seu entendimento sobre determinada questão jurídica, promovendo a sua superação, no futuro, em outro julgamento. O julgamento-alerta constitui-se em anúncio público de que há a possibilidade de mudança de entendimento, "mas a efetiva alteração não é obrigatória, nem para as instâncias inferiores, nem para o próprio tribunal. Vale dizer, pode haver o aviso sem que posteriormente a mudança de entendimento se verifique" (CABRAL, 2013, p. 34-35).

O signaling, por sua vez, constitui-se em reconhecimento, pela Corte, de que o precedente está defasado, mas que não será superado naquela oportunidade tendo em vista a necessidade de se proteger a segurança jurídica dos membros da sociedade que organizaram sua conduta de acordo com o precedente.

Ambas as técnicas - julgamento-alerta e signaling - possuem, em grande medida, importantes efeitos no que concerne à segurança jurídica, à ideia de continuidade e à abordagem de jurisdição contemporânea voltada a normas jurídicas para o futuro (future-law-approach) (CABRAL, 2013, p. 35). Realizando o julgamento-alerta, o tribunal transfere o risco de prejuízo pela alteração da estabilidade para o particular. Insta salientar que, mesmo que o julgamento-alerta reafirme a ratio decidendi, aquele não pode ser visto como algo dispensável, pois serviu para reabilitar a jurisprudência consolidada à luz de novos argumentos, sob uma discussão pluralista em outro contexto temporal (CABRAL, 2013, p. 36-37).

O objeto do presente estudo é a análise da decisão proferida pelo STF no julgamento da QO-AO 1814/ MG, a qual se configura, em nosso sentir, um típico caso de julgamento-alerta. Em certa medida, as conclusões aqui obtidas aplicam-se também à técnica da sinalização.

\section{A COMPETÊNCIA DO SUPREMO TRIBUNAL FEDERAL PARA CONHECER E JULGAR AÇÕES QUE VISAM A IMPUGNAR ATOS DO CNJ}

Escolheu-se como acórdão para análise aquele proferido pelo STF no julgamento da Questão de Ordem na Ação Originária 1814/MG, tendo como relator o ministro Marco Aurélio, cujo objeto é a discussão acerca da competência do STF em processar e julgar atos do Conselho Nacional de Justiça.

Inicialmente, tratou-se de ação pelo rito ordinário proposta por Juiz do Trabalho ante a União, pela qual se pretendeu o reconhecimento da ilegalidade e a declaração de nulidade de procedimento do Tribunal Regional do Trabalho da 3a ${ }^{2}$ Região e do CNJ, visando a impedir o desconto no respectivo subsídio do magistrado de valores recebidos indevidamente a título de adicional por tempo de serviço.

A petição inicial foi distribuída ao juízo federal de primeira instância que declinou da competência em favor do STF, entendendo ser aplicável o artigo 102, inciso I, alínea $r$, da Carta Magna. Enviada ao STF, a ação foi registrada como Ação Originária e autuada sob o no 1.814. A ação foi submetida a julgamento de Questão de Ordem para apreciar a competência do STF para o julgamento daquela causa.

O ministro relator Marco Aurélio votou pela incompetência do STF, aplicando entendimento firmado anteriormente em jurisprudência consolidada, pela qual o disposto no artigo 102, I, alínea $r$, da Constituição Federal, deve ser interpretado de forma restritiva, sendo competente o STF apenas para julgar ações constitucionais que visem à impugnação de atos do CNJ. Adotou-se, assim, a tese anteriormente esposada por aquele Tribunal de que, na hipótese de ser ajuizada ação ordinária perante a União, tendo como pano de fundo atos do CNJ, a competência há de ser da Justiça Federal e não do STF. 
Por seu turno, a ministra Rosa Weber especificamente cita os precedentes constituídos pelos Mandados de Segurança no 27.712 e no 29.118, pelos quais o STF somente tem competência para julgar as ações constitucionais, isto é, habeas corpus, mandado de segurança e habeas data, tendo como objeto atos proferidos pelo CNJ.

A profusão de "precedentes", citados pelos ministros do STF referentes a uma mesma questão jurídica, demonstra a inexistência de um sistema de precedentes judiciais vinculantes no Brasil. Não há um precedente claro sobre a questão, um leading case que seja continuamente citado como sendo o locus de extração da ratio decidendi e que tenha dado a interpretação do dispositivo em questão. A própria ratio decidendi não é claramente definida, pois alguns julgados dizem respeito apenas à competência do STF para o julgamento de mandado de segurança, enquanto outros referem-se às demais ações constitucionais.

O ministro Celso de Mello acompanhou o voto do ministro relator, embasado pelo precedente criado pelo próprio STF (AO 1.706-AgR/DF), reconhecendo a competência deste para julgamento de ações que visam a impugnar atos do CNJ apenas quando se cuidar de impetração de mandado de segurança, habeas data, habeas corpus ou mandado de injunção. Afirmou, ainda, que tal entendimento tem sido preponderante em diversos julgamentos recentes e de causas semelhantes, votando pelo reconhecimento da competência da Justiça Federal comum de primeira instância para processar e julgar, com fulcro no artigo 109, I, da Constituição Federal, aquela causa.

Houve, assim, por parte daqueles ministros do STF, clara aplicação de entendimento firmado em jurisprudência consolidada da Corte, pela qual se estabeleceu a seguinte interpretação a ser dada ao artigo 102, I, $r$, da Constituição Federal: nas ações que visem a impugnar atos do CNJ, somente as ações constitucionais são de competência originária do STF, sendo da Justiça Federal a competência para julgamento das demais ações. Adotou-se, assim, um critério formal-restritivo para definição da competência do STF ou da Justiça Federal para julgamento das ações que objetivam impugnar atos do CNJ.

A Suprema Corte concluiu pela aplicação do entendimento adotado em julgamentos anteriores, determinando a competência da Justiça Federal para o conhecimento, processamento e julgamento daquela ação ordinária, conforme disposto pelo artigo 109, inciso I, da Constituição Federal, em razão de a União ser parte no processo, não se aplicando a competência originária do STF prevista no artigo 102, I, $r$, da Constituição Federal, alvo de interpretação restritiva que limitou sua aplicação apenas às ações constitucionais.

Neste ponto, é necessário esclarecer, mais uma vez, que não temos ainda, no Brasil, uma prática judicial de precedentes judiciais em sentido semelhante ao que ocorre nos países do common law. Assim, verifica-se que os ministros do STF, no julgamento da QO-AO 1814/MG, fazem referência a diversos precedentes - e não a um leading case. O que há, de fato, no STF, é uma jurisprudência consolidada quanto à interpretação a ser dada ao artigo 102, I, $r$ da CF. Isto, entretanto, não prejudica nem altera as conclusões alcançadas no presente estudo.

\section{A TENTATIVA DE OVERRULING PELO MINISTRO DIAS TOFFOLI}

É sob a ótica da Ação Ordinária 1814/MG do STF que nos propomos a analisar a tentativa de overruling realizada pelo ministro Dias Toffoli, bem como expor a reação dos demais ministros à possibilidade de modificação do entendimento adotado pela jurisprudência consolidada do STF no que se refere à interpretação dada ao artigo 102, I, $r$ da CF. Todas as citações diretas e paráfrases deste capítulo foram feitas com base no voto do ministro Dias Toffoli proferida no julgamento da QO-AO 1814/MG.

No voto do ministro Dias Toffoli, verifica-se que ele pretende alterar o fundamento que disciplina a determinação da competência para julgamento de ações, visando a impugnar atos do CNJ, a saber:

a) interpretação da jurisprudência consolidada do STF referente ao artigo 102, I, r, da CF: utilização do critério formal para determinação da competência, de modo que apenas as ações constitucionais são de competência do STF, enquanto as demais ações são de competência da Justiça Federal;

b) superação da jurisprudência consolidada do STF, mediante alteração da interpretação a ser dada ao artigo $102, \mathrm{I}, r$, da CF, segundo entendimento do ministro Dias Toffoli, propugnando pela adoção de critério material de determinação da competência: seriam de competência do STF as ações que impugnam atos do CNJ que possam ser enquadrados em sua atuação finalística de disciplina e fiscalização e que possam repercutir 
frontalmente nos tribunais ou seus membros, ainda que não veiculadas por meio de ação constitucional, hipótese em que a submissão do julgamento à Justiça Federal poderia promover subversão na posição constitucional do CNJ que Ihe foi atribuída pela Constituição.

Ao final, o ministro Dias Toffoli votou por se reconhecer a incompetência do STF para conhecer e julgar aquela AO 1814, uma vez que o ato do CNJ atacado referia-se a mero ato administrativo, de ordem financeira, envolvendo o interesse de magistrados que se encontrem em situação específica.

Tanto pelo critério formal de interpretação do artigo 102, I, r, da CF (entendimento atual do STF), quanto pela utilização do critério material (proposto pelo ministro Dias Toffoli), o resultado alcançado é o mesmo. As consequências em termos de integridade e unidade do Direito, entretanto, são diferentes: o ministro Dias Toffoli pretende o overruling da ratio decidendi até então adotada pelo STF, superando-se a aplicação do critério formal para interpretação do artigo 102, I, r, da CF para, em seu lugar, aplicar o critério material apresentado. A adoção de nova interpretação do artigo 102, I, $r$, da CF lançaria seus efeitos para as demais ações futuras ou em trâmite de impugnação de atos do CNJ.

Logo, o ministro Dias Toffoli, em seu voto, a despeito de ter acompanhado o voto do ministro relator, valeu-se de fundamento determinante diferente. Esse fundamento diverso da ratio decidendi adotada na decisão em estudo pelo STF, ao contrário do que se poderia supor, no entanto, possui grande importância para o desenvolvimento do Direito, exercendo função semelhante aos chamados minority cases do Direito norte-americano: casos decididos contra uma tendência predominante de decisões tornam-se a principal maneira pela qual os juízes podem expressar pontos de vista contrários à tendência jurisprudencial vigente. Transmitem informações que, de outra forma, permaneceriam enterradas sob a decisão da maioria do tribunal. Embora não sejam diretamente aplicáveis como fonte de direito, os casos que não se conformam à tendência dominante servem como um sinal de divergência emergente no Judiciário. Os minority cases desempenham importante papel de signaling, influenciando informalmente decisões futuras (FON; PARISI, 2006, p. 525).

Nesse sentido, o ministro Dias Toffoli levantou algumas questões no sentido de lhe parecer temerária a redução do alcance do artigo 102, I, $r$, da CF, tendo como escopo a interpretação formal acerca do dispositivo. O ministro entendeu ser realmente necessário restringir o dispositivo, contudo a restrição deveria ser feita sob outro fundamento, uma vez que não deveria a interpretação do dispositivo ser realizada de acordo com a ótica meramente instrumental, sob pena de se promover o esvaziamento do conteúdo da norma. Segundo o ministro, deveria ser adotada a análise a partir de cada caso concreto, analisando-se o conteúdo do ato do $\mathrm{CNJ}$.

Para o ministro Dias Toffoli, a fim de que seja preservada a necessária e importante missão constitucional atribuída ao CNJ, a restrição interpretativa a ser realizada não pode deixar de lado a razão subjacente atinente à vontade do legislador quando da criação da norma constitucional: devem ser objetos de apreciação pela Corte Suprema todas aquelas ações que tenham relação com a autoridade dos tribunais ou com o regime disciplinar da magistratura. Ele posicionou-se no sentido de que descabe fazer qualquer delimitação de modo a admitir apenas as ações de cunho constitucional, uma vez que não foi essa a real intenção do legislador, intentando promover o overrruling do entendimento do STF, que adota o critério formal de restrição da competência do STF para julgamento de causas cujo objeto é a impugnação de atos do CNJ.

Defende Dias Toffoli a competência do STF quanto a: a) demandas relacionadas ao exercício do poder disciplinar do CNJ sobre os membros da magistratura; b) ações ante decisões do Conselho que desconstituam ato normativo ou deliberação de tribunal local relacionados a matérias a esse diretamente afetas; e c) outras em que a atuação do CNJ se dê, precipuamente, na consecução de sua atividade-fim, quando direta e especialmente incidente sobre membros e órgãos a ele diretamente subordinados.

Por outro lado, entende não ser a Corte Suprema competente para apreciar demandas cujos objetos sejam deliberações do CNJ que: a) atinjam tão somente servidores dos órgãos fiscalizados ou mesmo as serventias extrajudiciais fiscalizadas pelos tribunais locais; b) revejam atos administrativos gerais dos tribunais (assim considerados os que não se sujeitam à regulamentação distinta do Judiciário, de que seriam exemplos os relacionados a concursos públicos ou licitações dos tribunais locais); ou c) não digam respeito a ações de interesse exclusivo de toda a magistratura. 
Assim, de forma incisiva, o ministro Dias Toffoli pondera que um ato proferido pelo CNJ dentro de suas atribuições regimentais (âmbito finalístico e funcional) deve estar sob a tutela do STF. Desta forma, afirmou em seu voto que "os atos administrativos do CNJ - como os atos de qualquer órgão do Judiciário - se submetem à jurisdição de primeira instância (porque nenhuma subversão hierárquica pode daí decorrer)"; por sua vez, "os atos finalísticos, por outro lado, e tão somente os que digam respeito à missão precípua do Conselho (quais sejam: os que incidam frontalmente sobre interesses diretos de tribunais e membros da magistratura), devem ser submetidos à competência originária desta Corte".

O ministro Dias Toffoli propõe, em seu voto, uma alteração da interpretação que vinha sendo adotada pelo STJ acerca da interpretação restritiva a ser concedida ao artigo 102, I, r, da CF. Ele pretende superar o entendimento firmado que adota o critério formal de limitação da competência do STF apenas ao julgamento das ações constitucionais, substituindo-o por um critério material que leva em consideração não a natureza da ação, mas a natureza do ato do CNJ impugnado.

\section{O ALERTA DE POSSÍVEL SUPERAÇ̃̃O DE ENTENDIMENTO E AS CONSEQUÊNCIAS JURÍDICAS EM UM SISTEMA DE PRECEDENTES JUDICIAIS OBRIGATÓRIOS}

Na análise da QO-AO n. 1.814/MG ora sob exame, especial consideração se faz à reação dos demais ministros ao voto do Ministro Dias Toffoli, os quais, apesar de não concordarem com a realização do overruling, mostraram-se simpatizantes pela necessidade de superação do precedente (in casu, da jurisprudência consolidada do STF) e toda a argumentação no voto do ministro Dias Toffoli diante do caso em análise.

É perceptível que nos votos de alguns ministros que participaram do julgamento está exposta a intenção de que pretendem rever o entendimento adotado pelo STF, isto é, a sinalização na qual, em casos futuros e análogos, o posicionamento do ministro Dias Toffoli - em relação à adoção do critério material em substitução ao critério formal para definição da competência do Supremo Tribunal Federal para conhecer e julgar ações que visam a impugnar atos do CNJ - poderia ser aderido pelos demais ministros, viabilizando, assim, a realização do overruling.

O ministro Luis Roberto Barroso, em um primeiro momento, exaltou o voto do ministro Dias Toffoli, compartilhando da percepção levantada a respeito da importância do CNJ e em especial à sua competência. Tal reflexão, contudo, não foi suficiente para alterar o entendimento do ministro Roberto Barroso, o que não o impediu de, em meio à sua exposição, indicar que seu posicionamento poderia vir a mudar:

[...] eu estou acompanhando as manifestações do Ministro Teori Zavascki e do Ministro Marco Aurélio. Portanto, Presidente, eu estou aderindo à conclusão desses dois votos. Como a reflexão do Ministro Toffoli foi extremamente profunda e com alcance mais largo, eu gostaria de me reservar um pouco mais de tempo para refletir sobre os pontos que ele aventou, embora já antecipe, desde logo, que, em linha de princípio, estou de acordo com eles e que, portanto, o critério de seleção deva ser em relação à matéria e não um critério puramente formal. Mas não gostaria de me comprometer, de plano, com essa visão, com a qual tive contato hoje, mas devo dizer que fiquei seduzido por ela. De modo que, por ora, eu estou apenas acompanhando ambos os relatores e guardando para minha própria reflexão o voto do Ministro Dias Toffoli e os fundamentos que ele apresentou, que me parecem substanciosos, e devo dizer que me sinto inclinado a adotá-los também.

De forma semelhante, a ministra Rosa Weber expôs em seu voto indicação de que poderá, em julgamento futuro, aderir ao posicionamento do ministro Dias Toffoli, adotando o critério material em substituição ao critério formal para definição da competência do STF. Não o fez, porém, naquele julgamento, não aderindo seu voto à tentativa de overruling, mas podendo ser caracterizada indicação de mudança de seu entendimento em futuro julgamento. Confira-se trecho de seu voto no qual, claramente, a ministra Rosa Weber indica possível mudança de entendimento:

[...] por ora, na íntegra, não só a conclusão como os fundamentos que embasaram os votos dos eminentes Relatores, tanto o Ministro Marco Aurélio quanto o Ministro Teori Zavascki; sem deixar de louvar a reflexão profunda com que nos proporcionou - a mim, então, confesso, com muito gosto - o voto do eminente Ministro Dias Toffoli. Comprometo-me a refletir a respeito, mas por ora continuo a entender na linha do voto do Ministro Sepúlveda Pertence e na linha de decisões do Plenário desta Suprema Corte - belíssimos acórdãos da lavra de Vossa Excelência e do Ministro Celso de Mello. 
Continuarei a refletir, quem sabe, para amanhã ou depois aderir a uma compreensão que priorize não a classe, mas o tema. Senhora Presidente, com todo o respeito aos entendimentos contrários, não teria nenhuma dificuldade em entender que cabe submeter decisões de órgão administrativo à magistratura, mesmo de primeiro grau. Não veria, pessoalmente, nenhuma dificuldade; mas, como disse, continuarei a refletir sobre o tema.

Durante o debate, o ministro Luiz Fux mostrou-se relutante, num primeiro momento, em relação ao caminho percorrido pelos precedentes da Suprema Corte no controle dos atos do CNJ, conforme ressalta em seu voto:

[...] eu também deixaria só para um momento de reflexão dos Colegas, por exemplo, que uma solução que leve à denegação da competência do Supremo para o julgamento dos atos do CNJ pode encerrar a seguinte hipótese, como já ocorreu: o CNJ afasta um presidente de um tribunal, e esse afastamento do presidente do tribunal vai ser analisado com inversão hierárquica total por um juiz de Primeiro Grau.

Reconheceu, contudo, que deveria haver restrição da competência do STF em relação aos atos proferidos pelo CNJ, em especial aos processos objetivos de controle permeados por este último, conforme discorreu:

[...] entendi que o Ministro Dias Toffoli fez uns balizamentos expressivos e razoáveis, porque realmente a submissão de membros de hierarquia superior ao julgamento de integrantes da carreira em nível inferior poderia gerar, digamos assim, uma disfuncionalidade da própria razão de ser do CNJ. De sorte que eu acompanho o voto do Ministro Dias Toffoli.

O ministro Gilmar Mendes, por sua vez, destacou o questionamento levantado pelo ministro Dias Toffoli, aludindo "as próprias razões que marcaram a decisão do legislador constituinte, quando entendeu que colocar o CNJ na estrutura do Poder Judiciário significava também Ihe dar uma certa proteção institucional". Afirmou, ainda, que corrobora com o posicionamento trazido pelo ministro Dias Toffoli:

[...] compartilho dessa preocupação trazida pelo Ministro Toffoli e faria coro a essa proposta, trazida por Sua Excelência, de redução teleológica para que façamos a leitura do texto constitucional com esse ajuste. Estou sintetizando o que Sua Excelência já disse com todas as palavras no que diz respeito tanto às atividades disciplinares do CNJ de caráter positivo, porque, claro, também temos aqueles recursos que são dirigidos ao CNJ que se limitam a confirmar, mas isso já está resolvido em jurisprudência. Por isso estou chamando de atos de caráter positivo, deliberações positivas; e também as deliberações normativas ou regulamentares do CNJ.

Não obstante, o ministro Teori Zavascki afirmou seguir a jurisprudência consolidada estabelecida pela Corte, fundada "exclusivamente numa distribuição de competência com base no critério da natureza da ação". O ministro-relator ressaltou, no entanto, o voto do ministro Dias Toffoli, reconhecendo o seu impacto:

Todavia, também quero registrar que fiquei sensibilizado com o voto do Ministro Dias Toffoli e, portanto, não gostaria de fechar as portas no sentido de evoluir. Talvez, e isso fica aqui à meditação dos Colegas, se devesse conjugar os dois critérios. É que, se adotarmos apenas o critério de conteúdo, como o fez o Ministro Dias Toffoli, nós vamos ter um outro problema: os próprios mandados de segurança que não declinarem uma pretensão segundo aquele conteúdo seriam da competência do juiz de primeiro grau.

A presidente do STF, ministra Cármen Lúcia, expôs que a discussão proposta pelo ministro Dias Toffoli é de grande valia para a Casa, bem como abre caminho para novas reflexões acerca do tema, caracterizando a possibilidade de a Corte refletir sobre ele em julgamentos futuros:

Em primeiro lugar, Ministro Dias Toffoli, gostaria de elogiar o trabalho realizado por Vossa Excelência, que abre caminho para que possamos realmente refletir sobre tema da maior importância, e para que o Supremo Tribunal Federal possa, de alguma forma, sedimentar e consolidar ideias numa única diretriz, por ser o Conselho Nacional de Justiça instituição muito nova.

A Ação Ordinária 1814/MG, a despeito de ter sido reconhecida por unanimidade a incompetência do STF para seu conhecimento, caracterizou-se pela tentativa de overruling que o ministro Dias Toffoli pretendia promover. Além disso, podemos constatar que, mesmo alguns ministros não votando de acordo com a fundamentação do ministro Dias Toffoli, concordaram em revisar suas interpretações acerca do tema, caracterizando o alerta de possível superação do entendimento do STF, que adota o critério formal de restrição de competência do STF prevista no artigo 102, I, r, da CF. 


\section{SISTEMATIZAÇÃO DOS VOTOS PROFERIDOS NO JULGAMENTO DA AO 1814/MG}

No julgamento da AO 1814/MG, o STF, por unanimidade, reconheceu a incompetência daquela Corte para julgamento da ação, enviando-a à primeira instância da Justiça Federal.

A unanimidade do julgamento refere-se apenas ao dispositivo da decisão, que reconheceu a incompetência da Corte. O ministro Dias Toffoli, entretanto, para fundamentar seu voto, apresenta fundamentos determinantes diferentes da ratio decidendi adotada pelo STF em sua jurisprudência consolidada.

Trata-se de exemplo em que é possível vislumbrar a diferença entre a ratio decidendi e a norma jurídica concreta firmada no dispositivo da decisão: tanto a adoção do critério formal quanto a adoção do critério material, naquele específico caso, levariam à mesma consequência de reconhecimento da incompetência do STF. A mudança de critério para determinação da competência - do formal para o material -, alterando-se assim o entendimento do STF sobre a questão, todavia, poderia trazer resultados diferentes a outros julgamentos.

Em um sistema de precedentes judicias vinculantes (e também para o atual sistema de jurisprudência consolidada existente no Brasil), a importância recai sobre a ratio decidendi, isto é,, sobre os motivos determinantes da decisão.

Na tabela a seguir procuramos sistematizar os votos proferidos pelos ministros do STF no julgamento da AO 1814/MG:

\section{Votos dos ministros do STF na AO 1814/MG}

(Obs.: O ministro Ricardo Lewandowski não participou do julgamento. À época do julgamento, o STF encontravase com apenas 10 ministros em virtude da aposentadoria do ministro Joaquim Barbosa. Posteriormente, sua vaga seria preenchida com a nomeação do ministro Edson Fachin)

\begin{tabular}{|c|c|}
\hline $\begin{array}{l}\text { Marco Aurélio } \\
\text { (Relator) }\end{array}$ & $\begin{array}{l}\text { Aplicação da ratio decidendi da jurisprudência consolidada do STF: aplicação do critério formal } \\
\text { de determinação da competência do STF prevista no artigo } 102, I, r \text { da CF. }\end{array}$ \\
\hline Dias Toffoli & $\begin{array}{l}\text { Tentativa de superação da ratio decidendi da jurisprudência consolidada do STF: substituição } \\
\text { pela aplicação do critério material de determinação da competência do STF prevista no artigo } \\
102, l, r \text { da CF. }\end{array}$ \\
\hline Roberto Barroso & $\begin{array}{l}\text { Seguiu o relator, mas considerou a possibilidade de, em novo julgamento, alterar seu } \\
\text { entendimento: "De modo que, por ora, eu estou apenas acompanhando ambos os relatores e } \\
\text { guardando para minha própria reflexão o voto do ministro Dias Toffoli e os fundamentos que } \\
\text { ele apresentou, que me parecem substanciosos, e devo dizer que me sinto inclinado a adotá- } \\
\text { los também". }\end{array}$ \\
\hline Rosa Weber & $\begin{array}{l}\text { Seguiu o relator, mas comprometeu-se a refletir sobre o tema: "Continuarei a refletir, quem } \\
\text { sabe, para amanhã ou depois aderir a uma compreensão que priorize não a classe, mas o tema. } \\
\text { Senhora Presidente, com todo o respeito aos entendimentos contrários, não teria nenhuma } \\
\text { dificuldade em entender que cabe submeter decisões de órgão administrativo à magistratura, } \\
\text { mesmo de primeiro grau. Não veria, pessoalmente, nenhuma dificuldade, mas, como disse, } \\
\text { continuarei a refletir sobre o tema". }\end{array}$ \\
\hline Luiz Fux & Acompanhou o voto dissidente do ministro Dias Toffoli. \\
\hline Gilmar Mendes & $\begin{array}{l}\text { Seguiu o relator quanto ao dispositivo, mas em seu voto mostrou concordância com a } \\
\text { fundamentação trazida pelo ministro Dias Toffoli. }\end{array}$ \\
\hline Teori Zavascki & $\begin{array}{l}\text { Seguiu o voto do relator, mas admitiu a possibilidade de rever seu entendimento para adoção } \\
\text { de um critério misto: "Todavia, também quero registrar que fiquei sensibilizado com o voto do } \\
\text { ministro Dias Toffoli e, portanto, não gostaria de fechar as portas no sentido de evoluir. Talvez, } \\
\text { e isso fica aqui à meditação dos colegas, se devesse conjugar os dois critérios". }\end{array}$ \\
\hline Celso de Mello & Seguiu o voto do relator \\
\hline Cármen Lúcia & $\begin{array}{l}\text { Seguiu o voto do relator, mas ressaltou a possibilidade de que o assunto seja rediscutido: "Em } \\
\text { primeiro lugar, ministro Dias Toffoli, gostaria de elogiar o trabalho realizado por Vossa Excelência, } \\
\text { que abre caminho para que possamos realmente refletir sobre tema da maior importância, e } \\
\text { para que o Supremo Tribunal Federal possa, de alguma forma, sedimentar e consolidar ideias } \\
\text { numa única diretriz, por ser o Conselho Nacional de Justiça instituição muito nova". }\end{array}$ \\
\hline
\end{tabular}


Temos, no que se refere aos fundamentos determinantes da decisão, o seguinte panorama:

\begin{tabular}{|l|l|}
\hline Adoção do critério formal (jurisprudência consolidada do STF) & 6 votos \\
\hline Adoção do critério material (superação da ratio decidendi da jurisprudência consolidada do STF) & 3 votos \\
\hline Manifestação de possibilidade de mudança de entendimento em julgamentos futuros & 4 votos \\
\hline
\end{tabular}

Dos nove ministros que participaram do julgamento, três deles fundamentaram seu voto pela superação do critério formal de determinação da competência do STF, adotando o critério material para a interpretação da competência do STF prevista no artigo 102, I, $r$ do STF. Outros quatro ministros seguiram a ratio decidendi da jurisprudência consolidada do STF, mas manifestaram a possibilidade de modificarem seu entendimento em julgamentos futuros.

Da soma dos ministros que fundamentaram seus votos pela adoção de uma nova interpretação ao dispositivo em questão, com os ministros que anunciaram a possibilidade de modificação de seu entendimento, temos sete ministros, isto é, maioria absoluta do Plenário do STF, número suficiente para um futuro overruling da ratio decidendi da jurisprudência consolidada da Corte.

Havia, assim, número suficiente de ministros para se alterar o entendimento do STF sobre a questão jurídica debatida. Esperava-se que, em julgamentos futuros, a questão fosse novamente debatida, seja para manter, seja para alterar a ratio decidendi aplicada no julgamento da QO-AO 1814/MG. Não foi, porém, o que aconteceu, como veremos.

\section{DECISÕES POSTERIORES AO JULGAMENTO DA QO-AO 1814/MG}

Neste trabalho, a partir da análise da decisão proferida pelo STF na QO-AO 1814/MG, procurou-se analisar alguns aspectos próprios de um sistema que reconhece a autoridade do precedente judicial. Dentre eles ressalta-se o interessante fenômeno pelo qual o ministro Dias Toffoli tenta promover a superação de um entendimento jurisprudencial consolidado pelo STF, atingindo, entretanto, o mesmo resultado.

Procurou o ministro Dias Toffoli superar o entendimento do STF de que a competência da Suprema Corte para julgar as causas impugnativas de atos do CNJ prevista no artigo 102, I, $r$, da CF, deve ser limitada a partir de um critério formal: somente as ações constitucionais que visam à impugnação de ato do CNJ seriam de competência do STF, enquanto as demais ações, ditas ordinárias, seriam de competência da Justiça Federal. Trata-se de ratio decidendi estabelecida na jurisprudência consolidada do STF.

O ministro Dias Toffoli, entretanto, pretende superar esse entendimento substituindo o critério formal pelo critério material, de modo que seriam de competência do STF as ações que impugnem atos do CNJ que sejam capazes de serem enquadrados em sua atuação finalística de disciplina e fiscalização, que possam repercutir frontalmente nos tribunais ou seus membros, ainda que não veiculadas por meio de ação constitucional, hipótese em que a submissão do julgamento à Justiça Federal poderia promover subversão na posição constitucional do CNJ que Ihe foi atribuída pela Constituição.

No acórdão sob estudo, aplicando-se tanto o critério formal quanto o material, o resultado seria o mesmo: naquele caso específico, envolvendo determinação do CNJ de que o magistrado devolvesse aos cofres públicos valores recebidos considerados indevidos, a competência seria da Justiça Federal de primeira instância, e não do STF: pelo critério formal, por não se tratar de ação constitucional, e pelo critério material, uma vez que $\mathrm{o}$ ato do $\mathrm{CNJ}$ atacado refere-se a mero ato administrativo, de ordem financeira, envolvendo o interesse de magistrados que se encontrem em situação específica.

Trata-se de claro exemplo de que a ratio decidendi não se confunde com a norma jurídica estabelecida para o caso concreto. Houvesse o ministro Dias Toffoli obtido sucesso em sua tentativa de overruling, o resultado do julgamento da ação restaria inalterado: o reconhecimento da incompetência do STF para o julgamento daquela causa. Para fins de um sistema de precedentes judicias obrigatórios, entretanto, o resultado seria de grande importância: a alteração da interpretação do artigo 102, l, r, da CF, lançando seus efeitos para todas as demais ações a serem movidas que visem à impugnação de atos do CNJ.

A decisão analisada é, também, um dos raros casos em que se verifica a ocorrência da técnica do julgamento-alerta, pela qual a Corte sinaliza a possibilidade de que, em julgamento futuro, poderá reexaminar a questão para uma possível mudança de entendimento. Com a técnica do julgamento-alerta, a Corte procura 
minimizar os impactos deletérios à segurança jurídica, alertando a comunidade jurídica - e também a sociedade como um todo - sobre a possibilidade de se promover a superação de um determinado entendimento jurisprudencial.

Com o alerta promovido pelo STF no julgamento da QO-AO 1814/MG, entendemos que a ratio decidendi, adotada até então pelo STF em sua jurisprudência consolidada, de limitação de sua competência para julgamento de causas cujo objeto seja a impugnação de atos pelo CNJ aplicando-se o critério formal, deveria ser reexaminada pelo STF, para fins de:

a) promover, em definitivo, o overruling do entendimento, adotando-se o critério material para limitação da competência do STF estabelecida no artigo 102, I, r, da CF; ou

b) reafirmar a ratio decidendi adotada pela jurisprudência consolidada do STF de adoção do critério formal para limitação da competência do STF estabelecida no artigo 102, I, r, da CF.

Realizado o julgamento-alerta, a Corte precisaria manifestar-se novamente sobre a questão, seja para reafirmar o precedente judicial (ou, in casu, a jurisprudência consolidada do STF), seja para promover a sua superação, reestabelecendo a segurança jurídica sobre a interpretação e aplicação do referido dispositivo constitucional.

Ressalta-se, entretanto, que o Supremo Tribunal Federal não voltou a discutir o assunto, pois, em julgamentos posteriores, manteve o entendimento de definição da competência, utilizando-se o critério formal, sem que houvesse maiores considerações sobre a superação da ratio decidendi para adoção do critério material de fixação da competência.

Até mesmo os ministros que, no julgamento da QO-AO 1814, manifestaram sua intenção de rever seu posicionamento para fins de adoção do critério material de fixação de competência, não se manifestaram posteriormente em outros julgamentos envolvendo a mesma questão.

A título de exemplo, no julgamento do AgRg na AO 1.894/DF, em voto da lavra do ministro Roberto Barroso, houve a aplicação da ratio decidendi pela qual se adota o critério formal para fixação de competência do STF. Nenhuma consideração, entretanto, se fez sobre a tentativa de superação desta ratio decidendi, havendo, inclusive, invocação do julgamento proferido na QO-AO 1814/MG. Relembre-se que, no julgamento da QO-AO 1814/MG, o ministro Roberto Barroso manifestou-se no sentido de que precisaria de mais tempo para refletir a questão, "embora já antecipe, desde logo, que, em linha de princípio, estou de acordo com eles e que, portanto, o critério de seleção deva ser em relação à matéria e não um critério puramente formal", e que, embora não se comprometesse, naquele momento, "devo dizer que fiquei seduzido por ela".

Quanto ao atual posicionamento do ministro Dias Toffoli em relação à questão: Teria ele desistido de promover a superação do entendimento adotado pelo STF? O Ministro dias Toffoli manifestou-se, ainda que de forma não aprofundada, sobre a questão no julgamento do AgRg na AO 2.891/DF.

No AgRg na AO 2.891/DF, o recorrente pede a aplicação da tentativa de overruling havida no julgamento da QO-AO 1814-QO/MG pelo próprio ministro Dias Toffoli. O ministro Dias Toffoli, no entanto, no julgamento daquele recurso (AgRg na AO 2.891/DF), teve a oportunidade de reavivar sua tentativa de overruling da ratio decidendi aplicada pelo STF, mas não o fez. Confira-se, in verbis, a decisão do ministro Dias Toffoli sobre sua própria tentativa de overruling realizada anteriormente na QO-AO 1814-QO/MG:

Não obstante minha posição pessoal acerca do assunto, no sentido da competência desta Corte para o exame de demandas disciplinares de magistrados e das que interferem na autonomia dos Tribunais ainda que não veiculadas por ação mandamental (o que externei nos autos da AO no 1814-QO/MG e da ACO no 1680-AgR/ $\mathrm{AL}$ ), essa posição tem sido avaliada pontualmente por esta Corte em demandas nas quais a apreciação do ato do CNJ por magistrados de origem possa subverter a posição constitucional atribuída ao Conselho. Trata-se de apreciação individualizada que não tem recebido desta Corte o caráter de generalidade que a ela pretende atribuir o agravante. Ao contrário, a regra adotada ainda é a que explicita o descabimento de ajuizamento de demanda que refuja das hipóteses de ações tipicamente constitucionais, sendo, portanto, de se manter a decisão monocrática pelo não conhecimento do feito.

A decisão do ministro Dias Toffoli causa-nos certa estranheza: por certo que toda ação precisa ser analisada de forma individualizada, mas quando se trata de concretizar as garantias constitucionais da igualdade e da segurança jurídica, precisamos lidar com a aplicação sistematizada, coerente e íntegra das normas jurídi- 
cas. O entendimento firmado pelo Tribunal na ratio decidendi do precedente ou da jurisprudência consolidada precisa ter um mínimo caráter de generalidade, a fim de que possa abarcar casos materialmente iguais, concretizando o famoso brocardo jurídico de que casos iguais devem ser julgados de forma igual.

A necessidade de análise individualizada de cada caso demanda que esta individualização seja feita respeitando-se a racionalidade do ordenamento jurídico: toda decisão judicial deve estar localizada dentro de um sistema racional, orgânico, coerente e íntegro de decisões judiciais.

No caso em apreço - o julgamento do AgRg na AO 2.891/DF - o ministro Dias Toffoli, aparentemente, não abandonou seu entendimento de adoção do critério material para fixação da competência do STF, exposta como tentativa de overruling na QO-AO 1814/MG, mas afirmou que sua aplicação deve se dar de forma individualizada. Esta afirmação, todavia, não veio acompanhada da respectiva fundamentação pela qual o ministro: a) promovesse a distinção dos casos (distinguishing) e, a partir desta distinção, deixasse de aplicar a ratio decidendi em favor de um entendimento diverso; b) demonstrasse a semelhança jurídica do caso sob julgamento e dos casos passados sobre os quais foi construída a ratio decidendi.

Ademais, havendo a distinção dos casos, uma nova ratio decidendi deveria ser adotada para os casos não semelhantes ao daquele objeto da QO-AO 1814/MG, para, então, termos duas ratio decidendis, cada uma aplicada a um conjunto de fatos diversos. Nada, porém, disso é feito. A apreciação individualizada dos casos não pode levar a julgamentos isolados que firam a integridade do Direito e o caráter de harmonia que as decisões dos tribunais devem guardar entre si.

Nesse sentido, a advertência de Daniel Farber (2005, p. 1.183) é de que o respeito aos precedentes não significa simplesmente recusar-se a superar as decisões passadas, mas considerá-los seriamente como ponto de partida para a análise de casos futuros. Essa noção deriva parcialmente da fundamentação por analogia fundada na similaridade entre os fatos das causas, mas, mais importante, ela reflete a necessidade de dar confiança ao raciocínio das opiniões anteriores. $O$ desejo dos juízes de submeter-se dessa maneira a seus predecessores - e a expectativa deles de submissão similar de seus sucessores -, transforma a Corte de uma coleção de juízos individuais em constante mutação para uma instituição capaz de construir um corpo contínuo de direito ao invés de uma mera sucessão de regras aplicáveis uma única vez.

O tratamento individualizado de cada caso deve se dar como garantia de que o litígio receberá um julgamento adequado às suas peculiaridades, mas mesmo esta decisão singular deve guardar relação de harmonia e compatibilidade com o conjunto de outras decisões do tribunal, mantendo a possibilidade de compreensão racional do Direito.

Em síntese, após o julgamento-alerta promovido no julgamento da QO-AO 1814/MG, o STF não mais se manifestou adequadamente sobre a questão, seja para promover o overruling, seja para reafirmar a ratio decidendi, cuja correção do entendimento havia sido questionada por sete dos ministros do STF.

\section{CONSIDERAÇÕES FINAIS}

Há certo consenso de que não há, no Brasil, um sistema de precedentes judicias obrigatórios. Embora os precedentes judiciais e o sistema de stare decisis tenham sido objeto de inúmeros estudos e debates, estes não se fizeram acompanhar de uma prática jurídica adequada a um sistema de respeito à autoridade do precedente judicial.

No presente estudo, procedemos a abordagem do julgamento da QO-AO 1814/MG pelo STF, no qual o ministro Dias Toffoli procurou alterar o entendimento da Corte acerca da fixação de competência do STF para julgar ações que visem à impugnação de atos do CNJ.

A tentativa de mudança de entendimento veio acompanhada, naquele julgamento, de diversas manifestações dos outros ministros do STF, seduzidos pela nova abordagem trazida pelo ministro Dias Toffoli e indicações de que, em novo julgamento, poderiam seguir o novo entendimento apresentado, promovendo-se o overruling da ratio decidendi da jurisprudência consolidada da Corte.

Aparentemente, no entanto, a discussão caiu no esquecimento e o STF continuou, desde então, a aplicar o mesmo entendimento de aplicação do critério formal para fixação da competência do STF. O julgamento-alerta não foi seguido de nova discussão sobre a questão jurídica que: a) pudesse levar ao overruling do 
entendimento aplicado pela jurisprudência consolidada do STF; ou b) expressamente, e de maneira fundamentada, mantivesse o mesmo entendimento, informando à sociedade a manutenção da jurisprudência consolidada do STF.

A análise do julgamento da QO-AO 1814/MG e também do julgamento proferido no AgRg na AO 2891/ DF, no qual o recorrente demanda nova manifestação do ministro Dias Toffoli sobre seu posicionamento exarado na QO-AO 1814/MG, demonstra a possibilidade de que caia em descrédito a utilização das técnicas de sinalização e julgamento-alerta pela Corte Suprema, justamente dois dos mecanismos que deveriam ser utilizados como concretização da segurança jurídica em casos de alteração de entendimento jurisprudencial consolidado.

Quando, no julgamento da QO-AO 1814/MG, os ministros do STF manifestaram sua intenção de rediscutir um entendimento jurisprudencial consolidado, isto é, expressamente demonstraram a possibilidade de se promover a superação da ratio decidendi quanto à questão jurídica discutida, assumiu-se a responsabilidade, perante a sociedade e a comunidade jurídica, de reapreciar a questão, mantendo ou superando o entendimento até então adotado, e deveriam fazê-lo sob a égide da fundamentação qualificada.

Há muito, ainda, o que se fazer para a adoção de uma prática adequada de respeito, manejo e aplicação dos precedentes judiciais no Brasil.

\section{REFERÊNCIAS}

ÁVILA, H. Segurança jurídica: entre permanência, mudança e realização no direito tributário. São Paulo: Malheiros, 2011.

BRASIL. Constituição da República Federativa do Brasil. Brasília: Senado Federal, 1988.

BRASIL. Código de Processo Civil. Brasília: Senado Federal, 2015.

BRASIL. Supremo Tribunal Federal. Ação Originária 1814/MG. Tribunal Pleno. Relator ministro Marco Aurélio. Diário da Justiça da União Eletrônico 237. Julgado em 24/9/2014.

BRASIL. Supremo Tribunal Federal. Agravo Regimental na Ação Originária 2.891/DF. Tribunal Pleno. Relator ministro Dias Toffoli. Diário da Justiça da União Eletrônico 87. Julgado em 31/3/2017.

BRASIL. Supremo Tribunal Federal. Agravo Regimental na Ação Originária 1.894/DF. Primeira Turma. Relator ministro Roberto Barroso. Diário da Justiça da União Eletrônico 168. Julgado em 7/8/2018.

CABRAL, A. P. A técnica do julgamento-alerta na mudança de jurisprudência consolidada. Revista de Processo, São Paulo, ano 38, v. 221, p. 13-48, jul. 2013.

CAMBI, E. Jurisprudência Lotérica. Revista dos Tribunais, São Paulo, ano 90, v. 786, p. 108-128, abr. 2001.

CROSS, Rupert; HARRIS, James W. Precedent in English Law. 4. ed. Oxford: Clarendon Press, 2004.

DIDIER JR., F.; BRAGA, P. S.; OLIVEIRA, R. A. Curso de Direito Processual Civil: teoria da prova, direito probatório, decisão, precedente, coisa julgada e tutela provisória. 13. ed. Salvador: JusPodivm, 2018.

FARBER, D. A. The rule of law and the law of precedents. Minnesota Law Review, v. 90, n. 5, p. 1.173-1.203, 2005-2006.

FON, V.; PARISI, F. Judicial precedents in civil law systems: a dinamic analysic. International Review of Law and Economics, n. 26, p. 519-535, 2006.

MARINONI, L. G. Precedentes obrigatórios. 4. ed. São Paulo: Revista dos Tribunais, 2016.

MARINONI, L. G.; ARENHART, S. C.; MITIDIERO, D. Novo Código de Processo Civil Comentado. São Paulo: Revista dos Tribunais, 2015.

MELLO, Patrícia Perrone Campos; BAQUEIRO, Paula de Andrade. Distinção inconsistente e superação de precedentes no Supremo Tribunal Federal. Revista Brasileira de Políticas Públicas, Brasília, v. 8, n. 1, p. 667-688, 2018.

MITIDIERO, D. Cortes superiores e cortes supremas: do controle à interpretação, da jurisprudência ao precedente. São Paulo: Revista dos Tribunais, 2013.

POWELL JR., L. F. Stare Decisis and judicial restraint. Washington \& Lee Law Review, Lexington, v. 47, n. 2, p. 281-290, mar. 1990. 